\title{
ANALYSIS OF THE IMPACT OF MICROCLIMATE IN A ROOF SPACE ON A GOTHIC TRUSS CONSTRUCTION
}

\begin{abstract}
The research in the field of historical trusses, carried out at the workplace of authors for a long time, is focused on monitoring and analysing microclimate with the aim of specifying environmental conditions that would be suitable for preservation of a historical structure for further generations. Currently, this investigation is running together with a blanket screening of historical trusses in Slovakia [1 and 2]. In each truss, there was recorded the general technical state as well as the way of ventilation in a roof space. To define the impact of microclimate in a roof space on the lifetime period and sustainability of a historical truss, long-term measurements of features regarding both a roof space and its surroundings are made. The gothic truss over the gothic Roman-Catholic church of the Most Holy Body of Christ was chosen as an experimental truss for this type of analysis because it is very well-preserved.
\end{abstract}

Keywords: Historical truss, timber construction, relative air humidity, air temperature, absolute moisture of wood.

\section{Introduction}

With the effort of achieving the sustainability of the good technical condition of an involved truss, it is needful to analyse the effect of air humidity on moisture of timber structural elements. The object is to determine admissible (optimal and critical) conditions of microclimate in a roof space which are to be met to prevent arising acute moisture states in dependence on the way of ventilating in such a space. The marginal conditions that are taken into account are as follows:

- external environment (outdoor air temperature, relative air humidity, wind, rain, altitude,

location)

- internal environment (temperature, relative air humidity, air circulation)

Acute moisture states occur when exceeding the level of relative moisture on a surface, achieving the condensation point on the surface of a construction, and transcending equilibrium moisture in building materials with sorptive features (wood). Our study pays attention mainly to timber constructions which are historically valuable and are damaged due to the influence of acute moisture states. It is known that absolute moisture that is critical for occurring biotic forms of damage is as follows: around $10 \%$ for ligniperdous insects, more than $20 \%$ for dry rot, depending on the length of exposure [3]. The long-lasting influence of unfavourable conditions has a negative effect on physical and mechanical characteristics of timber components, and it consequently leads to degradation or other unwanted changes in statics of a building.

\section{The building and its truss in an experiment}

The Roman-Catholic church of the Most Holy Body of Christ was built as a stand-alone building, situated from the north to the west, in the middle of a fenced area in the historical centre of the village of Bela-Dulice (see Fig. 1). It probably arose in the first half of the 14th century. It has two separated truss structures, over the nave and the sanctuary. The truss over the nave was a subject of our investigation [2]. The steep truss over the nave has a rafter construction with collar beams, it is longitudinally bound with a central framed trestle (see Fig. 2), and it is dated from 1409d. It has 10 bonds, where 4 are full with 2 intermediate ones among them. In full bonds, central posts intersect collar beams; they are lapped over with rafters in the top. Symmetrical struts stabilize the post and join it with a tie beam. Rafters are mortised into the ends of tie beams. Tall oblique struts are used as a lateral reinforce. All joints are made using treenails. Central standing trestle is composed of a frame consisting of a sill beam, 4 posts which are, approximately in $3 / 5$, divided with horizontal struts. Symmetrical bottom struts stabilize the posts in longitudinal direction, like in transversal one. Diagonal struts serve as a bracing for the entire framed structure. There are 3 larger openings in the roof space: the passage opening in the parting gable between the trusses over the sanctuary, and a smaller one in the upper part over the roof ridge of the sanctuary. Additional openings are: an entrance into the tower, a continuous slot between roofing and a profiled cornice - Fig. 3. The truss was renovated more times in the past; about $60 \%$ of original wall plates were replaced in 2011. Approximately $80 \%$ of the truss construction preserved its originality up to the present days.

\footnotetext{
* ${ }^{1}$ Renata Korenkova, ${ }^{1}$ Peter Krusinsky, ${ }^{2}$ Peter Pisca

${ }^{1}$ Department of Building Engineering and Urban Planning, Faculty of Civil Engineering, University of Zilina, Slovakia,

E-mail: renata.korenkova@fstav.uniza.sk

${ }^{2}$ Department of Geodesy, Faculty of Civil Engineering, University of Zilina, Slovakia
} 


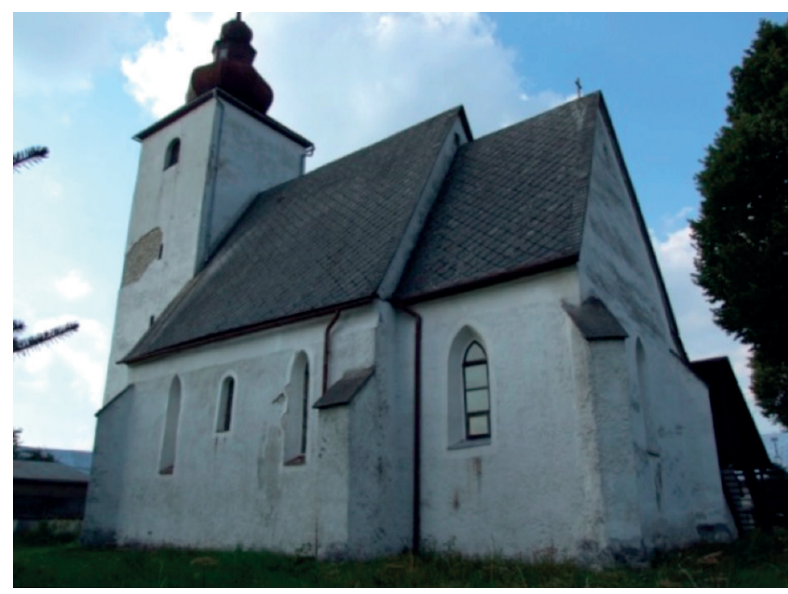

Fig. 1 The church of the Most Holy Body of Christ in the village of Bela-Dulice

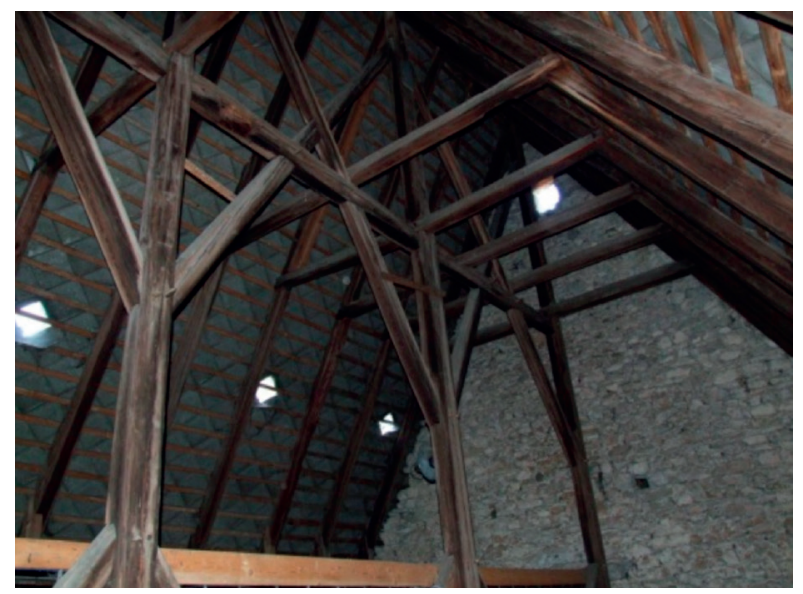

Fig. 2 View into the truss space

\section{Venting in the roof space}

The issue of venting in a roof space of a loft type is rather difficult. To make an airflow simulation in such a place, it is necessary to take account of all openings through which the air exchange between a roof space and the exterior could happen [4]. Most cases are difficult to definite openings like these; they are very often disordered, or they are irregular. In addition to the openings shown in Fig. 3, it is also needed to reckon with permeability of roofing, especially if it is made up e.g. of tiles. Then it is considered a permeable roof deck.

Nowadays, closed air layers are often used as a thermoinsulation. The air layer can be thought closed, when there isn 't any opening leading to a space and roofing is compact or it is airtight. Thermal resistance of the air layer depends on the thermal conductivity coefficient, and also on air circulation and heat radiation. Since the temperature of surfaces is various, the air on the warmer side is heated and moves up while the air on the colder side is cooled and moves down. This is air circulation - i.e. the exchange of heat by natural airflow (convection).

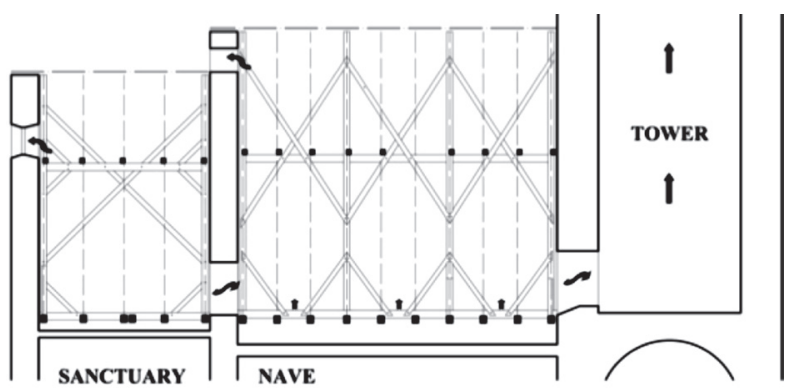

Fig. 3 The dispositional scheme of vents in the investigated truss, right - the truss cross-section, left - the truss longitudinal section

\section{Experimental measurements}

\subsection{The measuring system}

The examined pitched roof has a slope of $59^{\circ} 64^{\prime}$ [5] with gable walls. The roof deck comprises sheet copper roofing used in strips; the joints of particular strips have standing seams. As the roof space is open towards the outside - it has openings as in the lower so in the upper part of the roof deck, in the top of the gable wall, passage openings in the tower gable wall and in the truss gable wall over the sanctuary - the roof can be considered as a ventilated double-cladding pitched roof.

To enter reliable and real data into the airflow simulation, and to detect an actual as well as a long-term impact of microclimate in a roof space on the moisture accumulation in timber elements, the measuring system with two types of sensors for a particular space was designed. Particular temperature and relative air humidity sensors, and also sensors for scanning the temperature and absolute moisture of timber elements are found on spots where there is a precondition of airflow. Their disposition is symmetrical in relation to the roof ridge, i.e. they are disposed evenly on the western and southern side in the roof space. Some sensors are located in the lowest roof part, exactly in the exterior under the gutter cornice (sensor 01 and 02 ). Additional sensors have their positions in the exterior near the opening in the eastern

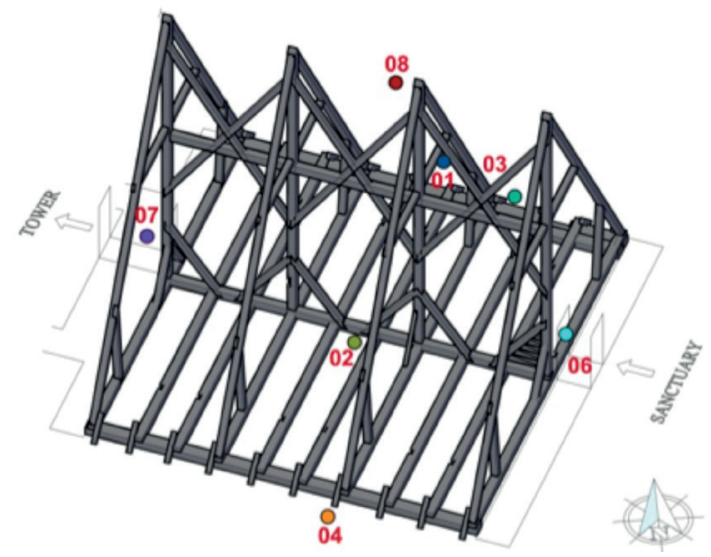

Fig. 4 The dispositional scheme of sensors V1 used as a measuring system 
gable wall, in openings in gable walls leading into trusses over the sanctuary (06) and into the tower (07). Other sensors are found in the roof space - in the middle of the object under the roof ridge (08), and in the midpoint of the roof plane length (03 and 04) see the scheme in Fig. 4.

\subsection{Microclimate in the roof space}

Temperatures and relative air humidity are monitored with sensors at 15-minutes intervals. For calculations, data gathered at 7:00, 14:00 and 21:00 o'clock within summer time, and at 8:00, 15:00 and 22:00 o'clock during winter time was considered - Fig. 5 and Fig. 7. Average day temperatures and relative air humidity are calculated using obtained data - Fig. 6 and Fig. 8. All evaluated data from sensors, as in spring so in autumn season, reached temperature maximums at 14:00 o clock - Table 1. Most sensors recorded temperature minimums at 7:00 o ' clock; and all sensors in autumn season. As to complete evaluation, sensor No. 8 (located closely to the roof ridge) recorded the highest temperatures at 7:00, 14:00 and also at 21:00 o ' clock. Relative air humidity goes to minimum in these spots. The roof ridge has no ventilation, thus there isn't any obvious airflow. There is sheet copper roofing used in strips on wooden slabs. The sensor No.07, found in the gable wall opening running into the tower, registered temperature minimums at 14:00 o' clock. At the same time, temperatures that were monitored with this sensor showed the smallest differences.

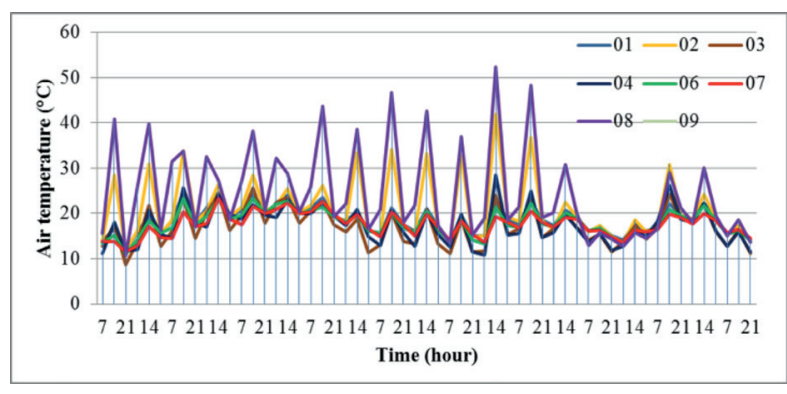

Fig. 5 The course of air temperatures recorded at 7:00, 14:00 and 21:00 o'clock - spring season 2012 (18.5.2012 - 5.6.2012)

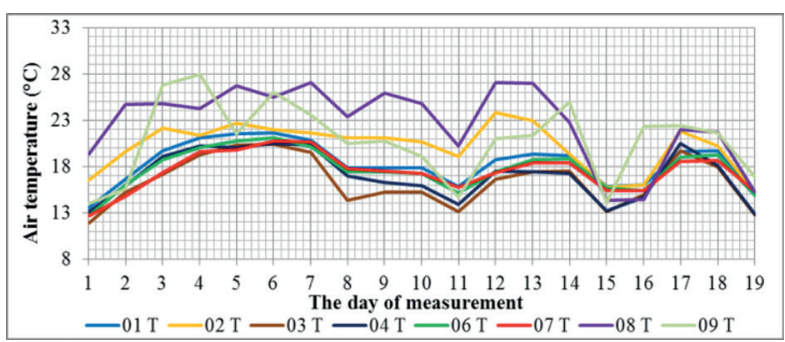

Fig. 6 Average day temperatures - spring season 2012 (18.5.2012 - 5.6.2012)

The tower has a square ground plan. It is made of stone and its walls are $800 \mathrm{~mm}$ thick. During daytime, there isn't any air overheating, and for the wall has high ability of accumulation, there isn't either any significant air cooling. And that's why there is no markedly cool air in early morning, in contrast to the truss space.

In most cases, temperature minimum was recorded with sensor No. 04, position of which is in the exterior on the northern side of a building, and with sensor No. 03 located near eaves in the exterior on the northern side of the building. Lowest temperatures in both seasons were found out using the outdoor sensor on the northern side of a building under the gutter cornice. Sensors No. 08 (under the roof ridge) and No. 02 (under roofing on the southern side of building) monitored considerable temperature fluctuations. It is these spots in the truss that air overheating occurs, which is caused by the effect of sunrays during the day.

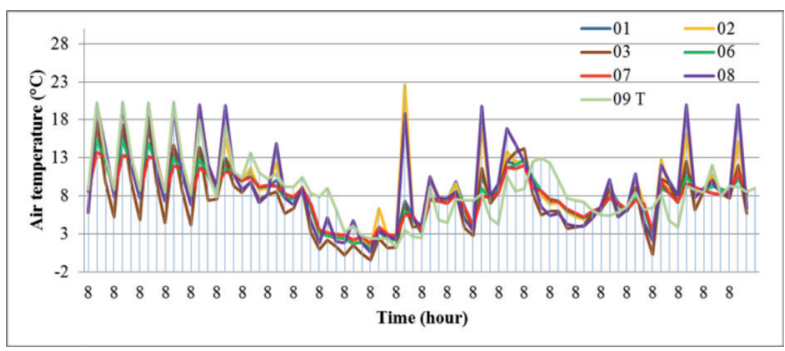

Fig. 7 The course of air temperatures recorded at 7:00, 14:00 and 21:00 o 'clock - autumn season 2012 (18.10.2012 - 13.11.2012)

Measured values of maximal and minimal temperatures in particular openings according to the scheme in Fig. 4

\begin{tabular}{|c|c|c|c|c|c|c|}
\hline \multirow{2}{*}{ Sensor No. } & \multicolumn{3}{|c|}{ Spring (18. 5. $2012-5.6 .2012)$} & \multicolumn{3}{|c|}{ Autumn (18. 10.2012 - 13.11. 2012) } \\
\hline & $7: 00$ & $14: 00$ & $21: 00$ & $8: 00$ & $15: 00$ & $22: 00$ \\
\hline 01 & Min & Max & & Min & $\operatorname{Max}$ & \\
\hline 02 & Min & Max & & Min & Max & \\
\hline 03 & & $\operatorname{Max}$ & Min & Min & Max & \\
\hline 04 & Min & $\operatorname{Max}$ & & Min & Max & \\
\hline 06 & Min & $\operatorname{Max}$ & & Min & Max & \\
\hline 07 & Min & Max & & Min & Max & \\
\hline 08 & & $\operatorname{Max}$ & Min & Min & $\operatorname{Max}$ & \\
\hline
\end{tabular}




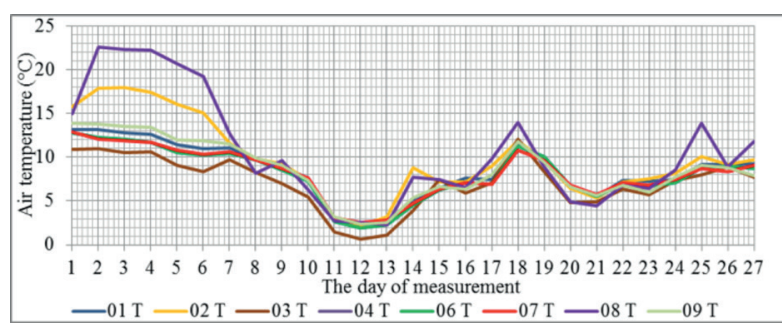

Fig. 8 Average day temperatures - autumn season 2012

(18.10.2012 - 13.11.2012)

\subsection{The impact of microclimate on moisture of timber}

Moisture of timber that is used in the roof space as a supporting truss structure ranges between $10-16 \%$. Its value is depending on relative air humidity in the space. Wood is a hygroscopic material that has the ability to change its moisture according to ambient air humidity - equilibrium moisture (sorption, desorption). Moisture of wood has direct effect on various forms of its deterioration. In praxis, it is not very easy to define its natural durability because it is affected by many factors. The most significant are factors like its constitution and an exposure to loading. The dependence of equilibrium moisture of wood on relative air humidity at the steady temperature is called the sorption isotherm. It can be defined by DEBOER and ZWICKER [6] as follows:

$$
\ln \frac{1}{\varphi}=\text { A.exp(-B.w) }
$$

where $\varphi$ is the relative air humidity (\%), w is the absolute moisture of wood (\%),

A,B are the coefficients having a linear shape [7], $T$ is the thermo-dynamical temperature $(\mathrm{K})$

$$
\begin{aligned}
& A(T)=7.7317-0.014348 . T \\
& B(T)=0.0087+0.000567 . T
\end{aligned}
$$

The comparison of measured values of timber components in relation to relative air humidity and thermo-dynamical air temperature may be set by the following formula:

$$
\mathrm{W}=-\frac{\ln \left(\frac{\ln \left(\frac{1}{\varphi}\right)}{A}\right)}{B}
$$

In accordance with calculations, absolute moisture of timber during the spring period in 2012 (see Fig. 9) fluctuated from 9.5 to $19.8 \%$. The highest values of moisture (average moisture of $13.2 \%)$ are related to the timber elements on the northern truss side near eaves; the lowest ones (average moisture of $8.23 \%$ ) regards the elements under the roof ridge. The highest values of moisture do not go over the critical limit which is optimal for arising such conditions that could cause damage of timber, e.g. ligniperdous insects, dry rot etc. [3].

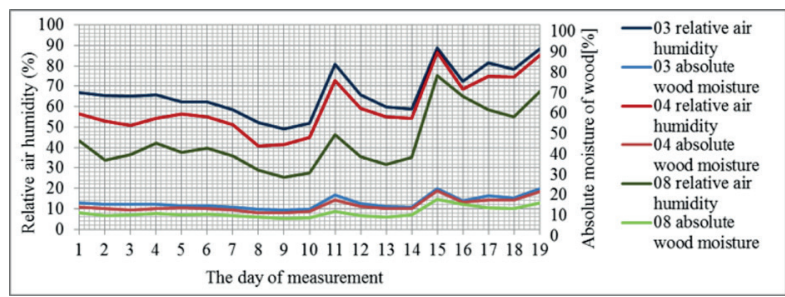

Fig. 9 The dependence of relative air humidity and absolute moisture of wood - calculated values, spring season 2012 (18.5. - 5.6.2012)

Absolute moisture values during the autumn period in 2012 (see Fig. 10) ranged between $10-27 \%$. Generally, relative air humidity is higher than in the spring and therefore moisture of timber elements is noticeably higher. The highest values of moisture (average 23.22\%) were found out in timber elements on the northern side of the truss structure near eaves; the lowest ones (average 13.61\%) concerned the timber elements under the roof ridge. In the view of the fact that moisture of timber elements exceeds critical values for the activity of ligniperdous pests, and the time during which the effect of higher relative air humidity is much longer, there is a high risk of occurring biotic damage of timber components.

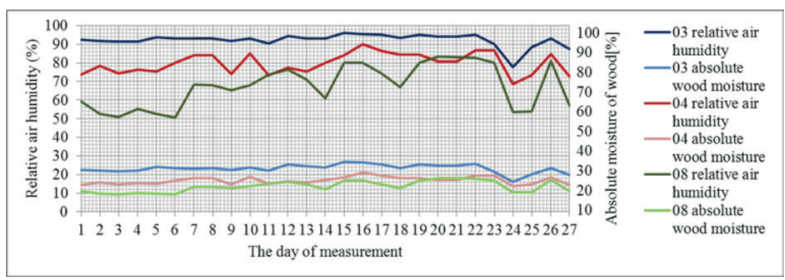

Fig. 10 The dependence of relative air humidity and absolute moisture of wood - calculated values, autumn season 2012 (18.10. - 13.11.2012)

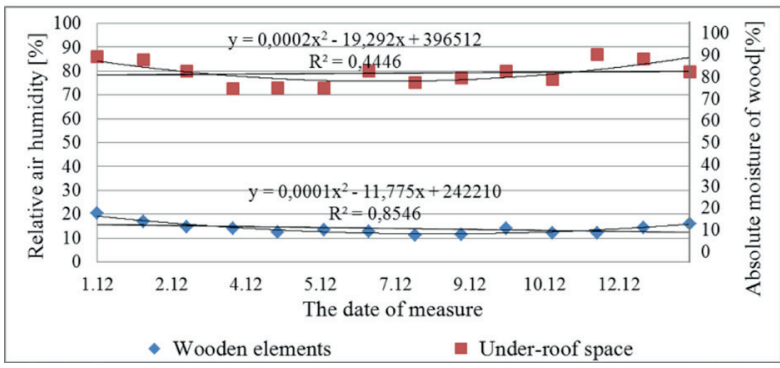

Fig. 11 Behaviour of relative air humidity in the roof space and values of absolute moisture, measured in timber elements of the fourth bond the village of Bela-Dulice [8]

Values of moisture in timber components were confronted with the values that were obtained by direct measurements with the device Greisinger. Measured relative air humidity in the roof space reached the values of outdoor air characteristics. Year-long measurements regarding moisture in timber components of the fourth bond indicated that average values of absolute moisture of wood exceeded $20 \%$ only in one case - in January. Next month average moisture was $17 \%$, and after that time values of moisture did not go over $13 \%$. As late as in winter season the values were higher than 16\% - see Fig. 11. 
Calculated values were compared with values of absolute moisture of timber elements that were measured with the hand-device within experimental measurements using resistant hygrometer Greisinger. Measured absolute moisture of wood moved on lower level, in critical seasons it did not overrun critical values of absolute moisture of wood. On the basis of data confrontation it is possible to suppose that under the influence of venting in specific spots or areas in the truss space, there is a local change of conditions in microclimate, which can be seen as a change of moisture in particular timber elements.

\section{Concluding remarks}

This case study describes the system of measuring characteristics of microclimate relating to the roof space of a historical truss and moisture in timber elements. It brings the results of temperature and relative air humidity measurements in two seasons - spring (18.5.2012 - 5.6.2012), and autumn (18.10. 2012 - 13.11.2012). Obtained data obviously indicate that there are considerable differences in air characteristics for individual openings in truss spaces during daytime; there are also noticeable temperature fluctuations in terms of building 's location regarding the cardinal points. In respect to the comparison of measured characteristics in particular openings of the truss space, it is possible to define the way of air circulation in this space and subsequently mark the spots wherein there is no airflow. This fact has a fundamental impact on the moisture content in involved timber components which are found on such places of the truss structure. The data differences associated with absolute moisture of timber elements, recorded by actual measurements as well as obtained by calculations, point out presumable effect of ventilating in the truss space on the moisture content in timber. Thus, the influence of microclimate in the roof space on moisture of timber components can be evaluated with consideration of their position. The lifetime of used timber components is connected with moisture affecting them for a long time. Measurements of airflow velocity in selected openings were also made in the evaluated spring period. They ranged from 0.25 to 1.15 m.s-1 [8], while wind velocity in the exterior at the time of measurements reached $3.3 \mathrm{~m} . \mathrm{s}-1$. It is very important to know real air circulation in spaces of historical trusses for creating such conditions that are convenient for preservation of valuable timber constructions. All data, which were got by methodical long-term measurements, form the groundwork for making airflow simulation in given space. This simulation is the second step of our experiment. Inputs for simulation will be specified with respect to actually measured airflow velocities.

This contribution is the result of the project implementation under the Culture Ministry of the Slovak Republic with number MK-5913/2011/1.3.

\section{References}

[1] SUCHY, L., KRUSINSKY, P., GRUNOVA, Z., DURIAN, K., ZACHAROVA, D., KORENKOVA, R.: Historical Trusses in Region of Orava and Kysuce, Zilina: M. Gibala KNM, ISBN 978-80-970171-1-8, 2010

[2] SUCHY, L., KRUSINSKY, P., BABJAKOVA, Z., DURIAN, K.: Historical Trusses of Sacral Objects in Turiec, Zilina: M. Gibala KNM, ISBN 978-80-965547-9-7, 2008

[3] REINPRECHT, L.: Wood Protection, TU Zvolen, 2008

[4] KORENKOVA, R.: Analysis of Historical under Roof Space Trusses, 36. Mezinarodni vedecka konference kateder a ustavu pozemniho stavitelstvi, Brno : VUT Brno 2012, ISBN 978-80-214-4536-9, pp. 49-52

[5] CAPKOVA, E., KRUSINSKY, P.: Geometric Analysis of Gothic Roman Catholic Church Roof in the Village of Bela-Dulice, IX. intern. scientific conference FCE TUKE, May 22-25, 2012, ISBN 978-80-553-0905-7

[6] CHRISTEN SKAAR: Wood-Water Relations, Springer Verlag, Berlin, 1988, ISBN 978-3-642-73685-8

[7] SIAU, J. F.: Transport Processes in Wood, Springer Verlag. ISSN 0043-7719, 1984

[8] KORENKOVA, R.: Effect of Microclimate Historic Truss under Roof Space on the Timber Construction, Stavebne hmoty, ISSN 1336-6041, vol, 9, No. 1, pp. 24-27, 2013. 